\title{
THE EFFECT OF WORKLOAD CAUSED BY THE PANDEMIC ON DEPRESSION, ANXIETY AND STRESS LEVELS IN SURGICAL AND OPERATING ROOM NURSES
}

\author{
Sultan Ozkan, Hayriye Aktas Unlu ${ }^{2}$ \\ ${ }^{1}$ Aydin Adnan Menderes University, Faculty of Nursing, Department of Surgical Diseases Nursing, Aydin, Turkey. \\ ${ }^{2}$ Aydin State Hospital, Aydin, Turkey \\ Address for Correspondence: Assist. Prof. Sultan Ozkan PhD, RN, E-mail: sultanozkan2000@yahoo.com \\ Received: 17.01.2021; Accepted: 20.05.2021; Available Online Date: 27.05.2021 \\ (C) Copyright 2021 by Dokuz Eylül University, Institute of Health Sciences - Available online at https://dergipark.org.tr/en/pub/jbachs
}

Cite this article as: Ozkan S, Aktas-Unlu H. The Effect of Workload Caused by the Pandemic on Depression, Anxiety and Stress Levels in Surgical and Operating Room Nurses. J Basic Clin Health Sci 2021; 2: 134-143.

\begin{abstract}
Purpose: To determine the effect of pandemic workload on depression, anxiety and stress levels in surgical and operating room nurses.

Methods: study is planed a descriptive and cross-sectional . This study sample was 166 nurses $(92 \%$ of all surgical nurses) working in surgical units a state hospital, all of whom agreed to participate in this study july $1,2020$.

The data were collected by personal information form, the workload Questionnaire and the Depression, Anxiety, Stress Scale-21. Number, mean, SD, percentage calculations, t test, ANOVA test, the Spearman correlation test and multivariate linear regresyon were used for data analysis

Results: The mean age of the nurses was $38.75 \pm 8.38$ years, $86 \%$ were women, $78 \%$ were undergraduate, $63 \%$ chose their profession willingly, $64 \%$ reported high stress in the pandemic and $64.5 \%$ high workload. When nurses who chose voluntarily and nurses who do not voluntarily choose their profession were compared, a statistically highly significant difference was found between the mean workload scores. As a result of the variance analysis performed between the departments (operating room, surgical intensive care units, surgical clinics) and DASS-21 and the mean scores of all subdimensions and workload scales, the difference between the units was found to be statistically significant $(p<.05)$.

Conclusion: More attention should be paid to the mental health of surgical nurses after pandemics. It is necessary to reduce the workload in order to prevent post traumatic syndrome. Taking steps to make them psychologically strong will be effective in balancing their mental state.
\end{abstract}

Keywords: Workload, depression, anxiety, stress, pandemi, surgical nursing

\section{INTRODUCTION}

The new type of coronavirus that emerged in WuhanChina in December 2019 was named Covid-19 by the World Health Organization (WHO). It has spread to many countries and has been identified as a pandemic (1). Various social restriction precautions have been taken by central authorities and health units around the world. However, it has spread rapidly and caused more than 75 million diagnoses and 1.6 million deaths globally (2). It is known that healthcare professionals are at serious risk and are infected with Covid-19 14 times more than other segments of the 
society, become sick, disabled, or even die $(3,4)$. This situation may cause long-term psychological consequences such as unwillingness to work, resignation, high levels of stress, and symptoms of anxiety and depression (5). Nurses, who have a significant proportion among healthcare professionals (3/4), play a front line role in the management of the pandemic $(1,6)$. Many healthcare professionals, including nurses, experience distress, anxiety, and other mental health problems during the pandemic $(1,7)$. International Labour Organization defines the main source of work-related stress for nurses as emotional stress due to excessive workload (6). Under these circumstances, the coping skill rate of nurses begins to fall, however, this change is often neglected (1).

Surgical units are complex and stressful units, having a high-risk environment for surgical nurses and patients as these units have a possibility of infection, injury, and exposure to dangerous substances and require long-term physical intimacy and a rapid decision-making process (8). Nursing care is most needed in surgical clinics, both due to the high number of patients and due to patients' dependence on nurses in terms of meeting personal needs (6). The care of patients who have undergone surgical operations becomes more comprehensive and more time-consuming than other patient groups (8). The increase in time spent for patients, the lack of materials and personal protective equipment, the shortage of human resources, equipment preparation, increased work intensity with additional precautions, and the obligation to distance themselves from loved ones negatively affect the emotional state of surgical nurses who work intensively, and it may cause a decrease in work efficiency $(1,7)$. The information obtained from this study, which investigates the effect of Covid-19 pandemic-related increase in the workload of surgical nurses on depression, anxiety, and stress, is undeniably important to understand the factors that may affect the work-related efficiency of surgical nurses and to provide a basis for necessary measures.

\section{METHODS}

This is a descriptive and cross-sectional study conducted to determine the pandemic-related workload and depression, anxiety, stress scale (DASS-21) scrores of surgical nurses, and to create a comprehension to understand whether the workload level affects DASS-21, or not.

The research was carried out in Aydın State Hospital operating room, surgical intensive care units, and surgical clinics in July 2020, during working hours. Among the 220 nurses working in these units, 166 nurses who agreed to participate in the study and filled out the forms completely were included in the study. The research data were collected daily between $16: 00$ and $17: 00$ by the researcher using face-to-face interview method. The daily routines of the nurses and the institution were not affected while the study was carried out.

\section{Data Collection Tools}

Introductory Information Form: In addition to the questions about the socio-demographic characteristics of the nurses, additional questions were asked about workload, the measures taken to prevent the spread of the coronavirus in the unit during the Covid-19 pandemic, and the competence of personal protective equipment.

\section{Depression, Anxiety and Stress Scale (DASS-21):} The validity and reliability study of DASS-21, the short version of DASS- 41 which was created by Lovibond and Lovibond (1995), was conducted by Sarıçam (2018). On this scale, there were 21 questions (7 questions each about depression, anxiety, and stress). A Likert-type rating scale (0-Never, 1Sometimes, 2-Often, 3-Always) was also used. For the evaluation of the scale, the scores obtained were summed up and the degree (normal, mild, moderate, advanced, very advanced) of the related problem was determined (9). In this study, Cronbach alpha ( $\alpha$ ) was found as .87 for depression, .85 for anxiety, and .86 for stress. These values show that the scale used in this study has a high reliability.

Workload Scale: The validity and reliability study of the scale developed by Duxbury and Higgins (1994) was conducted by Aycan and Eskin (2005) (10). The experiences of the participants in terms of workload, incompatibility, and the loss of control at work were evaluated on this scale by asking 11 questions. 5 points Likert scale ranging from 1 (strongly disagree) to 5 (strongly agree) was used for each item and higher scores indicated higher workload. The scale min-max score was $11-55$. In this study was $(\alpha)=.87$. 
Table 1. Introductory Informations of Nurses and Their Status According to Some Variables $(n=166)$

\begin{tabular}{|c|c|c|c|}
\hline & & Number (n) & Percent (\%) \\
\hline \multirow{4}{*}{$\begin{array}{l}\text { Age range } \\
\left(38.75 \pm 8.38^{*} \min -\max =19-61\right)\end{array}$} & $18-29$ & 29 & 17.5 \\
\hline & $30-39$ & 44 & 26.5 \\
\hline & $40-49$ & 79 & 47.6 \\
\hline & Over 50 & 14 & 8.4 \\
\hline \multirow[t]{2}{*}{ Gender } & Male & 23 & 13.9 \\
\hline & Woman & 143 & 86.1 \\
\hline \multirow[t]{2}{*}{ Marital status } & Single & 64 & 38.6 \\
\hline & Maried & 102 & 61.4 \\
\hline \multirow[t]{3}{*}{ Level of education } & High School,Vocational & 17 & 10.2 \\
\hline & Undergraduate & 129 & 77.7 \\
\hline & Postgraduate & 20 & 12.0 \\
\hline \multirow[t]{4}{*}{ Professional Experience } & $0-9$ years & 49 & 24.7 \\
\hline & $10-19$ years & 72 & 36.4 \\
\hline & $20-29$ years & 58 & 29.3 \\
\hline & $30-39$ years & 19 & 9.6 \\
\hline \multirow[t]{3}{*}{ Working Unit } & Operating room & 39 & 23.5 \\
\hline & Surg.Intensive Care Unit & 51 & 30.7 \\
\hline & Surgical Clinics & 76 & 45.8 \\
\hline \multirow[t]{2}{*}{ Smoking } & Yes & 71 & 42.8 \\
\hline & No & 95 & 57.2 \\
\hline \multirow[t]{2}{*}{ Chronic Disease } & Yes & 136 & 81.9 \\
\hline & No & 30 & 18.1 \\
\hline \multirow[t]{2}{*}{ Do you have children? } & Yes & 118 & 71.1 \\
\hline & No & 48 & 28.9 \\
\hline \multirow[t]{2}{*}{ Desired Selection of the Profession } & Yes & 105 & 63.3 \\
\hline & No & 61 & 36.7 \\
\hline \multirow{3}{*}{$\begin{array}{l}\text { The degree of stress experienced in the } \\
\text { pandemic (between } 1 \text { and } 10) \\
(7.67 \pm 2.05)^{*}\end{array}$} & Low & 11 & 6.6 \\
\hline & Middle & 49 & 29.5 \\
\hline & High & 106 & 63.9 \\
\hline \multirow[t]{3}{*}{ How he evaluates his workload } & little & 14 & 8.4 \\
\hline & middle & 45 & 27.1 \\
\hline & much & 107 & 64.5 \\
\hline
\end{tabular}

* Mean \pm Standart Deviation

\section{Statistical analysis}

The SPSS version 22.0 (SPSS Inc., Chicago, USA) software package was used for statistical analyses. Normality of the variables was analyzed with skewness, kurtosis, Kolmogrov-Smirnov test and the Shapiro-Wilk test. For normally distributed data, statistical differences between groups were evaluated using parametric tests (independent samples t-test and one-way ANOVA). When a statistically significant difference was observed in the one-way analysis of variance, "Bonferroni post hoc testing" evaluation was performed to compare the groups among themselves in order to see where the difference originated. In parametric variables, correlation test was used to determine the relationship between two variables. Multivariate linear 
Table 2. According to some Variables Nurses' Comparison of DASS-21, Depression, Anxiety, Stress Sub-Dimensions and Workload Scale Mean Scores

\begin{tabular}{|c|c|c|c|c|c|}
\hline & & $\begin{array}{l}\text { DASS-21 } \\
\text { Depression scores } \\
(7.32 \pm 4.83)\end{array}$ & $\begin{array}{l}\text { DASS-21 } \\
\text { Anxiety scores } \\
(5.42 \pm 4.24)\end{array}$ & $\begin{array}{l}\text { DASS-21 } \\
\text { Stress scores } \\
(7.33 \pm 4.43)\end{array}$ & $\begin{array}{l}\text { Workload Scale } \\
\text { Score } \\
(34.45 \pm 9.00)\end{array}$ \\
\hline \multirow[t]{3}{*}{ Gender } & Women & $7.22 \pm 4.82$ & $5.49 \pm 4.24$ & $7.30 \pm 4.43$ & $34.73 \pm 9.15$ \\
\hline & Men & $7.95 \pm 4.95$ & $4.95 \pm 4.31$ & $7.56 \pm 4.54$ & $32.69 \pm 7.92$ \\
\hline & $P$ value & $t=-.67 \quad p=.502$ & $t=.56 \quad p=.573$ & $t=-.26 \quad p=.792$ & $t=1.00 \quad p=.315$ \\
\hline \multirow[t]{3}{*}{ Marital status } & Single & $7.75 \pm 5.00$ & $5.95 \pm 4.41$ & $7.29 \pm 4.26$ & $36.59 \pm 8.93$ \\
\hline & Married & $7.05 \pm 4.73$ & $5.08 \pm 4.11$ & $7.36 \pm 4.56$ & $33.10 \pm 8.82$ \\
\hline & $P$ value & $t=.89 \quad p=.372$ & $t=1.28 \quad p=.202$ & $t=-.09 \quad p=.926$ & $t=2.47 p=.015^{*}$ \\
\hline Age Range & $18-29$ & $7.79 \pm 5.45$ & $5.86 \pm 4.28$ & $7.58 \pm 4.35$ & $38.65 \pm 7.54^{a}$ \\
\hline \multirow[t]{4}{*}{$(38.75 \pm 8.38)$} & $30-39$ & $7.68 \pm 4.41$ & $5.52 \pm 4.29$ & $8.13 \pm 4.37$ & $34.86 \pm 8.84$ \\
\hline & $40-49$ & $6.86 \pm 4.70$ & $5.06 \pm 3.92$ & $6.77 \pm 4.26$ & $33.18 \pm 9.05^{\mathrm{a}}$ \\
\hline & Over 50 & $7.85 \pm 5.76$ & $6.21 \pm 5.82$ & $7.50 \pm 5.63$ & $31.57 \pm 9.79$ \\
\hline & $P$ value & $F=.46 \quad p=.707$ & $F=.46 \quad p=.712$ & $F=.94 \quad p=.423$ & $F=3.26 p=.023^{*}$ \\
\hline \multirow{4}{*}{$\begin{array}{l}\text { Level of } \\
\text { education }\end{array}$} & H. Sch,Vocati & $6.88 \pm 4.24$ & $5.29 \pm 3.83$ & $6.47 \pm 3.55$ & $34.11 \pm 9.18$ \\
\hline & Undergraduate & $7.27 \pm 4.89$ & $5.41 \pm 4.24$ & $7.44 \pm 4.64$ & $34.31 \pm 8.96$ \\
\hline & Postgraduate & $8.00 \pm 5.07$ & $5.60 \pm 4.76$ & $7.35 \pm 3.75$ & $35.65 \pm 9.44$ \\
\hline & $P$ value & $F=.27 \quad p=.764$ & $F=.025 \quad p=.975$ & $F=.363 p=.696$ & $F=.203 p=.817$ \\
\hline Adequate & Yes & $5.60 \pm 4.19$ & $4.20 \pm 3.58$ & $5.79 \pm 3.53$ & $31.97 \pm 8.00$ \\
\hline \multirow[t]{3}{*}{ Precautions } & No & $8.34 \pm 4.81$ & $6.23 \pm 4.44$ & $8.28 \pm 4.61$ & $36.88 \pm 9.02$ \\
\hline & $P$ value & $t=-3.32 p=.001^{*}$ & $t=-2.72 p=$ & $t=-3.27 p=.001^{*}$ & $t=-3.16 p=.002^{*}$ \\
\hline & & & $.007^{*}$ & & \\
\hline Adequate & Enough & $5.70 \pm 4.39$ & $4.36 \pm 3.93$ & $6.19 \pm 4.44$ & $31.76 \pm 8.33$ \\
\hline \multirow[t]{3}{*}{ Equipment } & Not enough & $7.96 \pm 4.81$ & $5.84 \pm 4.30$ & $7.78 \pm 4.36$ & $35.51 \pm 9.06$ \\
\hline & $P$ value & $t=-2.77 p=.006^{*}$ & $t=-2.04 p=$ & $t=-2.11 p=.036^{*}$ & $t=-2.45 p=.015^{*}$ \\
\hline & & & $.043^{*}$ & & \\
\hline Desired Selection & Yes & $6.77 \pm 4.72$ & $5.13 \pm 4.14$ & $6.57 \pm 4.26$ & $32.60 \pm 9.06$ \\
\hline \multirow[t]{2}{*}{ of the Profession } & No & $8.27 \pm 4.90$ & $5.91 \pm 4.39$ & $8.65 \pm 4.44$ & $37.62 \pm 8.01$ \\
\hline & $P$ value & $t=-1.95 p=.053$ & $t=-1.15 \quad p=.252$ & $t=-2.90 \quad p=.003^{*}$ & $t=-3.58 p=.001^{*}$ \\
\hline
\end{tabular}

${ }^{*} p<.05$, F: One Way Analysis of Variance (ANOVA) test, $t$ : $t$ test, Mean \pm Standard Deviation, Upper lowercase letters show the statistical significance in paired comparisons.

regression analysis was conducted to test workload the effect on the DASS-21 variable. The results were given as mean \pm standard deviation and categorical variables as number, percentage and min-max.

Results with $p<.05$ were considered statistically significant.

\section{Ethics and Permissions}

Permission was obtained from the Non-Invasive Clinical Research Ethics Committee (03/07/2020E.34763, N:50107718-050.99) of the ADU Nursing Faculty and from the Ministry of Health to work on the Covid-19 outbreak and obtain permission from Aydın Provincial Health Directorate in order to carry out the research in Aydın State Hospital. Before the data is collected, the nurses who make up the sample are informed about the subject, purpose and it has been committed that the data will not be used outside of research and that the necessary confidentiality will be provided.

\section{RESULTS}

The average age of the nurses participating in the study was $38.75 \pm 8.38$ min-max $=19-61$, weekly working hours were $45.48 \pm 7.06$ min-max $=32-72$, and the number of night shifts per week was $1.80 \pm 0.77$ $\min -\max =0-3.86 \%$ of the nurses were women, $47.6 \%$ were between the ages of $40-49,77.7 \%$ were undergraduate, $63.3 \%$ of them reported that they chose their profession willingly, $63.9 \%$ experienced high stress during the pandemic and $65 \%$ had heavy workload (Table 1).

It has been found that the DASS-21 average score of the nurses $(20.08 \pm 12.60)$ is low, however, depression and stress are higher than anxiety subdimension. Also, the workload average is above the average, and the workload scale average score of single nurses is higher. As a result of the advanced 
Table 3. According to the Units in which Nurses Work, Comparison of DASS-21 Depression, Anxiety, Stress and Workload Scores and Self-reported Stress Level

\begin{tabular}{|c|c|c|c|c|c|c|c|}
\hline & Working Unit & $N$ & $\bar{x}$ & ss & Min - Max & $\boldsymbol{F}$ & $P$ \\
\hline \multirow{4}{*}{$\begin{array}{c}\text { Stress } \\
\alpha=.86\end{array}$} & Operating Room ${ }^{\mathrm{a}, \mathrm{b}}$ & 39 & 5.33 & 3.18 & $0-14$ & \multirow{4}{*}{7.05} & \multirow{4}{*}{$.001^{*}$} \\
\hline & Surg.Intensive Care Unit ${ }^{\mathrm{a}, \mathrm{b}}$ & 51 & 8.74 & 3.65 & $1-17$ & & \\
\hline & Surgical Clinics ${ }^{a}$ & 76 & 7.42 & 5.08 & $0-18$ & & \\
\hline & total & 166 & 7.33 & 4.43 & $0-18$ & & \\
\hline \multirow{4}{*}{$\begin{array}{c}\text { Depression } \\
\alpha=.87\end{array}$} & Operating Room a,b & 39 & 4.66 & 2.88 & $0-11$ & \multirow{4}{*}{10.99} & \multirow{4}{*}{$.001^{*}$} \\
\hline & Surg.Intensive Care Unit ${ }^{a, b}$ & 51 & 9.21 & 4.83 & $0-21$ & & \\
\hline & Surgical Clinics ${ }^{a}$ & 76 & 7.42 & 5.06 & $0-18$ & & \\
\hline & total & 166 & 7.32 & 4.84 & $0-21$ & & \\
\hline \multirow{4}{*}{$\begin{array}{c}\text { Anxiety } \\
\alpha=.85\end{array}$} & Operating Room ${ }^{a, b}$ & 39 & 3.46 & 2.79 & $0-9$ & \multirow{4}{*}{7.41} & \multirow{4}{*}{$.001^{*}$} \\
\hline & Surg.Intensive Care Unit ${ }^{\mathrm{a}, \mathrm{b}}$ & 51 & 6.80 & 3.53 & $0-17$ & & \\
\hline & Surgical Clinics ${ }^{a}$ & 76 & 5.50 & 4.91 & $0-19$ & & \\
\hline & total & 166 & 5.42 & 4.24 & $0-19$ & & \\
\hline \multirow{4}{*}{$\begin{array}{c}\text { DASS-21 } \\
\alpha=.94\end{array}$} & Operating Room ${ }^{a, b}$ & 39 & 13.46 & 7.81 & $0-33$ & \multirow{4}{*}{9.87} & \multirow{4}{*}{$.001^{*}$} \\
\hline & Surg.Intensive Care Unit ${ }^{\mathrm{a}, \mathrm{b}}$ & 51 & 24.76 & 11.11 & $1-50$ & & \\
\hline & Surgical Clinics ${ }^{a}$ & 76 & 20.34 & 14.10 & $0-54$ & & \\
\hline & total & 166 & 20.08 & 12.61 & $0-54$ & & \\
\hline \multirow{4}{*}{$\begin{array}{c}\text { Workload Scale } \\
\quad \alpha=.87\end{array}$} & Operating Room ${ }^{a, b}$ & 39 & 27.46 & 8.48 & $11-52$ & \multirow{4}{*}{28.15} & \multirow{4}{*}{$.001^{*}$} \\
\hline & Surg.Intensive Care Unit ${ }^{\mathrm{a}, \mathrm{b}}$ & 51 & 39.92 & 6.59 & $23-52$ & & \\
\hline & Surgical Clinics ${ }^{a}$ & 76 & 34.36 & 8.19 & $16-52$ & & \\
\hline & total & 166 & 34.45 & 9.00 & $11-52$ & & \\
\hline \multirow{4}{*}{$\begin{array}{c}\text { Self-reported } \\
\text { Stress Level } \\
\text { (between } \\
1-10)\end{array}$} & Operating Room ${ }^{a, b}$ & 39 & 6.71 & 1.90 & $3-10$ & \multirow[t]{4}{*}{5.19} & \multirow[t]{4}{*}{$.006^{*}$} \\
\hline & Surg.Intensive Care Unit ${ }^{a, b}$ & 51 & 8.33 & 1.87 & $1-10$ & & \\
\hline & Surgical Clinics ${ }^{a}$ & 76 & 7.71 & 2.08 & $2-10$ & & \\
\hline & total & 166 & 7.66 & 2.05 & $1-10$ & & \\
\hline
\end{tabular}

${ }^{{ }} p<.05, F$ : One Way Analysis of Variance (ANOVA) test, Upper lowercase letters show the statistical significance in paired comparisons.

analysis conducted to reveal the significant difference between the age groups and the workload scale average scores, it has been identified that the difference occurs between 18-29 and 40-49 age groups. For the questions "Do you think that the unit you work has taken sufficient precautions to prevent the spread of coronavirus?" and "Do you think that the equipment provided to you during the pandemic process is sufficient?", the average scores of all scales are high. The workload scale average of those who think that adequate precautions were taken $(31.97 \pm 8.00)$ is statistically and significantly different from the nurses who think the opposite $(36.88 \pm 9.02)$ $(p<.05)$. Likewise, the workload scale average of those who think that the equipment provided by the hospital was sufficient in the pandemic (31.76 \pm 8.33$)$ is statistically and significantly different from those who think the opposite $(35.51 \pm 9.06)(p<.05)$. When nurses who chose their profession willingly and those who did not voluntarily choose their profession were compared, a statistically significant difference was found between the workload scale average scores. Accordingly, it can be said that nurses who willingly choose their profession $(32.60 \pm 9.06)$ have less workload perception and can tolerate their jobs more than nurses who do not voluntarily choose their profession $(p<.001)$ (Table 2$)$.

As a result of the variance analysis, the difference between the units was found to be statistically significant $(p<.05)$. After post-hoc paired comparisons, DASS-21 sub-dimensions were found 
to be significant between surgical intensive care units and operating room employees, and the workload scale average scores were significant on each unit basis. The stress level defined by nurses for themselves (between 1-10) was also found to be significantly higher in surgical intensive care unit employees (Table 3).

According to the DASS-21 conversion table, "Normal", "Mild", "Moderate", "Advanced", "Very Advanced" classification was converted as "Moderate", "Advanced", and "Very Advanced". As a result of the variance analysis, a statistically significant difference was found. In the advanced analysis, the averages of sub-dimensions were found to be significantly higher (Table 4).

No significant correlation was found in the correlation analysis conducted between DASS- 21 and its subdimensions and depression, anxiety, stress, age, occupational experience, weekly working hours, and the number of night shifts per week, however, there was a very weak and negative correlation with age and professional experience. A very weak and positive correlation between weekly working hours and the number of night shifts was also found. As the weekly working hours and the number of night shifts per week increase, the average score of DASS-21 also increases. A significant correlation was found between workload scale and age, professional experience, weekly working hours, and the number of night shifts per week (respectively; $r=-.22, r=-.22$, $r=.17, \quad r=.28, p<.05)$. As age and professional experience increase, the workload scale average score decreases significantly. A weak and positive correlation was found between workload scale and weekly working hours and the number of night shifts per week (Table 5).

By using independent variables, which are the workload and self-reported stress level (between 1 and 10 ) in the nurses, a multivariate linear regression analysis was conducted to test the effect on the DASS-21 variable (Table 6).

As a result of the analysis, it was found that there was a significant regression model $(F(2,163)=30.07$; $p<.001$ ), and $26 \%$ of the variance in the dependent variable $\left(R^{2}\right.$ adjusted $\left.=.26\right)$ was explained by the independent variables. On the other hand, when the significance tests of the independent variables included in the model were examined, it was found that the workload scale had a positive and significant effect on DASS-21 $(\beta=.28 ; t(163)=3.84 ; \quad p<.001$, $\left.p r^{2}=.08\right)$. It was observed that the stress levels reported by the nurses themselves positively and significantly affected DASS-21 $\quad(\beta=.33 ; \quad t=4.48$; $p<.001, p r^{2}=.11$ ) (Figure 1).

\section{DISCUSSION}

In the study nurses were operating room nurses $(24 \%)$, surgical intensive care unit nurses $(31 \%)$, and

Table 4. Comparison of Differences the Surgical Nurses' Workload Mean Scores and Transformed Depression, Anxiety and Stress Levels

\begin{tabular}{|c|c|c|c|c|c|c|c|}
\hline & & $N$ & $\bar{x}$ & SS & Min - Max & $F$ & $P$ \\
\hline \multirow{3}{*}{$\begin{array}{c}\text { Depression } \\
\text { Level }^{*}\end{array}$} & Moderate $^{a}$ & 125 & 33.12 & 8.97 & $11-52$ & 6.38 & $.002^{*}$ \\
\hline & Advanced & 19 & 36.94 & 6.82 & $21-50$ & & \\
\hline & Very advanced $^{a}$ & 22 & 39.81 & 8.69 & $19-50$ & & \\
\hline \multirow{3}{*}{ Anxiety Level* } & Moderate $^{a}$ & 124 & 32.91 & 8.61 & $11-52$ & 9.02 & $.001^{*}$ \\
\hline & Advanced & 13 & 36.00 & 10.98 & $15-52$ & & \\
\hline & Very advanced $^{a}$ & 29 & 40.34 & 7.25 & $21-50$ & & \\
\hline \multirow{3}{*}{ Stress Level ${ }^{*}$} & Moderate $^{a}$ & 142 & 33.73 & 8.79 & $11-52$ & 4.86 & $.009^{*}$ \\
\hline & Advanced & 19 & 37.00 & 9.66 & $16-50$ & & \\
\hline & Very advanced $^{a}$ & 5 & 45.00 & 3.08 & $40-47$ & & \\
\hline & Total & 166 & 34.45 & 9.00 & $11-52$ & & \\
\hline
\end{tabular}

${ }^{*} p<.005, F$ : One Way Analysis of Variance (ANOVA) test, $N$ : Sayı, $\bar{X}$ : Mean \pm Standard Deviation,

Min-Max: Minimum value - Maksimum value, Upper lowercase letters show the statistical significance in paired comparisons. 
Table 5. Correlation Analysis Between Surgical Nurses' DASS-21, Scale Subgroups and Workload Scores in Pandemic and Some Variables $(n=166)$

\begin{tabular}{|c|c|c|c|c|c|c|c|c|c|c|}
\hline & \multicolumn{2}{|c|}{ DASS-21 } & \multicolumn{2}{|c|}{ depression } & \multicolumn{2}{|c|}{ anxiety } & \multicolumn{2}{|c|}{ stress } & \multicolumn{2}{|c|}{ Workload } \\
\hline & $r$ & $p$ & $r$ & $p$ & $r$ & $p$ & $r$ & $p$ & $r$ & $p$ \\
\hline Age & -.08 & .338 & -.07 & .372 & -.04 & .582 & -.10 & .220 & $-.22^{* *}$ & $.005^{\star}$ \\
\hline $\begin{array}{l}\text { Professional Experience } \\
\text { (years) }\end{array}$ & -.10 & .223 & -.08 & .310 & -.08 & .338 & -.11 & .151 & $-.22^{\star \star}$ & $.005^{*}$ \\
\hline $\begin{array}{l}\text { Weekly working hours in } \\
\text { a pandemic }\end{array}$ & .03 & .665 & .08 & .327 & -.00 & .978 & .02 & .851 & $.17^{*}$ & $.027^{*}$ \\
\hline $\begin{array}{l}\text { Number of weekly night } \\
\text { shift in a pandemic }\end{array}$ & .02 & .763 & .04 & .641 & .01 & .859 & .01 & .860 & $.28^{\star \star}$ & $.001^{* *}$ \\
\hline
\end{tabular}

surgical clinic nurses (46\%). Since individuals spend most of their time in their working environment, it is important.

The emotional state of the employees is shaped according to the conditions of that environment. The level of stress the employees are experienced and the problems they encounter come together to affect the individual's emotional involvement in the institution. Moreover, surgical nurses work in a highly stressful environment and have high workloads and stress due to their working environment $(7,11)$. In this study, the workload scale average scores of surgical nurses were found to be significantly higher in all subdimensions of DASS-21 in the very advanced category. The low job performance of the stress factor in nursing is considered to be a costly problem in terms of employee health (7). Studies have shown that pandemics increase the stress level of nurses when they cope with the intense emotional, physical, and cognitive demands $(5,12,13)$. Lai et al. (2020) reported a high rate of depression, anxiety, insomnia, and distress in the cross-sectional study in which the mental health results among the healthcare professionals treating Covid-19 patients in China were examined (5). In another study conducted in China, important symptoms of post-traumatic stress disorder were observed in $40.2 \%$ of healthcare professionals (13). In the study conducted by Chen et al. (2020), the importance of protecting the mental health of healthcare professionals to control infectious diseases better was emphasized (12). Liu et al. (2020) stated that $88 \%$ of nurses were concerned that Covid-19 could pose a pandemic threat, and this feeling increased their distress(1). Their most common concerns were reported as the risk of infection in family members or relatives (92\%), their risk of infection (89\%), and the risk of isolation from the family and society $(77 \%)$. In this study, all scale dimensions and the stress level defined by nurses were significantly higher in surgical intensive care unit employees. It can be said that the nurses working in surgical intensive care units have higher DASS-21 sub-score averages compared to the employees working in the operating room and clinic, and intensive care unit nurses can tolerate their work less, due to their higher perception of workload.

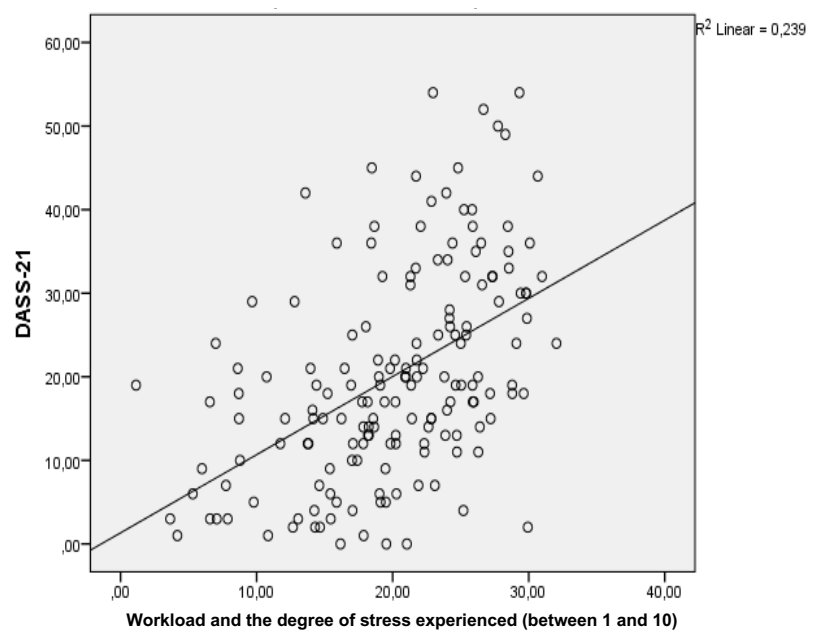

Figure 1. Regression Analysis Model between Surgical Nurses' Workload Scale Scores and Stress Perceptions DASS-21 
Table 6. Regression Analysis Between Surgical Nurses' Workload Scale Scores and Stress Perceptions DASS-21 in Pandemic

\begin{tabular}{|c|c|c|c|c|c|c|c|c|}
\hline \multirow[t]{2}{*}{ Model } & & \multirow{2}{*}{$\begin{array}{c}\text { Standardized } \\
\text { Coefficients }\end{array}$} & \multirow[t]{2}{*}{$\mathrm{t}$} & \multirow[t]{2}{*}{ Sig. } & \multicolumn{2}{|c|}{$95,0 \%$ Confidence Interval for B } & \multicolumn{2}{|c|}{ Collinearity Statistics } \\
\hline & & & & & Lower Bound & Upper Bound & Tolerance & VIF \\
\hline \multirow[t]{3}{*}{1} & (Constant) & & -2.37 & .019 & -16.85 & -1.54 & & \\
\hline & Workload Scale & .28 & 3.84 & $.000^{*}$ & .19 & .60 & .82 & 1.22 \\
\hline & Stress Perceptions (0-10) & .33 & 4.48 & $.000^{*}$ & 1.14 & 2.93 & .82 & 1.22 \\
\hline
\end{tabular}

${ }^{*} \mathrm{p}<.001$, VIF: Variance İnflation Factor, Adjusted R Square=.26,

Fernandez et al. (2020) stated that nurses work to ensure the highest quality of care provided in a stressful healthcare environment during times of crisis, such as natural disasters and epidemics (14). Professional organizations make suggestions that in times of crisis such as a pandemic, weekly total working hours should not exceed 40 hours. It is also emphasized that working hours and night shifts should be reduced as much as possible, considering that working intensively and having excessive workload accelerate the nurses' exhaustion (15). The nurses in this study work an average of 45 hours a week and have about 2-night shifts. As the weekly work and the number of night shifts of nurses increase, the average score of DASS-21 increases, however, as age and professional experience increase, the workload scale average score decreases significantly. Similarly, in another study, it was found that experienced nurses have low perceptions of workload (11).

On the other hand, Lai et al. (2020) stated that $61 \%$ of all participants in their study were nurses and women reported more severe depression, anxiety, and distress symptoms, and the level of anxiety among female nurses was founded as higher than other healthcare workers like the others (16-17). In this study, the rate of female nurses was $86 \%$, and $64 \%$ of the nurses reported the stress they experienced in the pandemic as high while $65 \%$ reported their workload as high.

As it was reported by Lai et al. (2020), eighty percent of nurses taking care of Covid-19 patients thought the pandemic was dangerous, and they were very concerned about infecting their families and friends. The reason why more than three-quarters of the nurses reduced their social interactions was the fact that they did not know if the patients they treated were infected or not, and most of them did not have adequate protective equipment.

Chen et al. (2020) noted that the nurses in the hospital where the study was conducted were concerned about the lack of protective equipment and the feelings of inadequacy when they encountered critically sick patients. In the study of Manzano Garcia and Ayala Calvo (2020), it was emphasized that due to the lack of personal protective equipment, increased workload, and the shortage of materials and personnel, it became difficult for nurses to carry out their daily work, and it caused them to be exposed to unnecessary risks (18). Therefore, personal protective equipment that nurses and all other healthcare professionals need should be provided and its sustainability should be ensured (15). In this study, depression, anxiety, and stress levels were found to be significantly higher in those who thought that the measures provided by the hospital were not sufficient and that the personal protective equipment provided by the hospital was insufficient. The issue that was experienced as the most common workload by the participants of this study was personal protective equipment with a rate of $65 \%$.

The study conducted by Ocal et al. (2015) showed that $33 \%$ of surgical nurses willingly chose their profession and were satisfied with their profession. In this study, $63 \%$ of nurses reported that they chose their profession willingly. When nurses who chose their profession willingly and those who did not voluntarily choose their profession were compared, a statistically significant difference was found between the workload scale average scores. As the stress level of those who expressed that they chose this profession voluntarily is lower, the precautions may be taken by investigating the reasons for especially those who chose this profession unwillingly.

Moreover, the workload scale and the stress levels reported by the nurses themselves have a positive and significant effect on DASS-21. As the workload and perceived stress of the nurses' increases, their depression, anxiety, and stress levels also increase. As a result of the study, it has been understood that the workload affects depression, anxiety, and stress. 


\section{CONCLUSION}

Nurses working in surgical units have serious difficulties due to the emotional problems that emerged as a result of workload. Most of these problems are temporary and unnoticeable in general. By identifying the stressful situations for nurses working in surgical units where work stress is intense, the studies on reducing the level of stress and enhancing the conditions can be planned and necessary measures can be taken. While planning the number of employees at health facilities, surgical nurses should be supported. It is important to take due precautions in terms of post-traumatic syndrome after the coronavirus pandemic. In this regard, surgical nurses should be supported and encouraged with training to raise their awareness about methods of coping with stress and reducing workload. In future studies, projects should be developed to enable surgical nurses to express themselves emotionally, and the impact of the developed projects on nurses should be monitored and evaluated.

\section{Limitations}

This study has certain limitations. Samples included in the study were relatively small group and single center. Additionally in times of global crisis, nurses may under-declare their anxiety levels.

Conflict of Interest: No conflict of interest was declared by the authors.

Financial Disclosure: The authors declared that this study has received no financial support.

Compliance with Ethical Standards: Approval was obtained from the ethics committee of Aydin Adnan Menderes University, Nursing Faculty (Approval: 03/07/2020-E.34763, Number: 50107718050.99). Permission from Ministry of Health to work for the Covid19 outbreak and permission obtain from Aydın Provincial Health Directorate in order to carry out the research in Aydın State Hospital

*This article presented at the Congress on Research-Publication and Education Processes in COVID-19 Pandemic Oral Presentation held on 15-16th jan, 2021, Izmir, Turkey.

\section{REFERENCES}

1. Liu Y, Long Y, Cheng Y, Guo Q, Yang L, Lin Y, et al. Psychological impact of the covid-19 outbreak on nurses in china: a nationwide survey during the outbreak. Front Psychiatry. 2020;11:1-11.

2. WHO. COVID-19 Weekly epidemiological update 20201012-weekly-epi-update

3. TTBB Press briefing. Turkish Medical Association 8th Month Evaluation of COVID-19 Pandemic. 2020.
4. Erdem $\mathrm{H}$, Lucey DR. Healthcare worker infections and deaths due to COVID-19: A survey from 37 nations and a call for WHO to post national data on their website. Int J Infect Dis. 2021;102:239_ 41.

5. Lai J, Ma S, Wang Y, Cai Z, Hu J, Wei N, et al. Factors associated with mental health outcomes among health care workers exposed to coronavirus disease 2019. JAMA Netw open. 2020;3(3):e203976.

6. Ocal D, Kurklu S, Tekin K. Determining the stress and motivation levels of the nurses working at the surgery clinics of atraning and research hospital. Heal Care Acad J. 2015;2(3):147.

7. Akbolat M. Does work-family conflict of healthcare personnel faced in business life affect their organizational commitment?: example of Sakarya province. Hacettepe Health Administration Journal. 2016;19(2):153-169.

8. Karabulut N, Çetinkaya F. Motivation levels and difficuilties encountered in the patient care of the nurses working in surgery clinics. J Anadolu Nurs Heal Sci. 2011;14(1):14-23.

9. Sarıcam $\mathrm{H}$. The psychometric properties of turkish version of depression anxiety stress scale-21 (DASS-21) in health control and clinical samples. JCBPR. 2018;7(1):19-30.

10. Aycan Z, Eskin M. Childcare, spousal, and organizational support in predicting work-family conflict for females and males in dual-earner families with preschool children. Sex Roles. 2005;53(7):453-71.

11. Karacabay K, Savcı A, Comez S, Celik N. Determination of the relationship between workload perceptions and medical error tendencies of surgical nurses. Mersin University Health Science Journal 2020;13(3):404-17.

12. Chen J, Liu X, Wang D, Jin Y, He M, Ma Y, et al. Risk factors for depression and anxiety in healthcare workers deployed during the COVID19 outbreak in China. Soc Psychiatry Psychiatr Epidemiol 2021;56:47-55

13. Cao W, Fang Z, Hou G, Han M, Xu X, Dong J, et al. The psychological impact of the COVID-19 epidemic on college students in China. Psychiatry Res 2020;287:112934

14. Fernandez R, Lord H, Halcomb E, Moxham L, Middleton R, Alananzeh I, et al. Implications for COVID-19: A systematic review of nurses' experiences of working in acute care hospital 
settings during a respiratory pandemic. Int J Nurs Stud. 2020;111: 103637.

15. Turkish Nurses Association. COVID-19 Nurse training guide and care algorithms. 2020;1-221.

16. Mo $Y$, Deng L, Zhang L, Lang Q, Liao C, Wang $\mathrm{N}$, et al. Work stress among Chinese nurses to support Wuhan in fighting against COVID-19 epidemic. J Nurs Manag. 2020;28(5):1002-9.

17. Shanafelt T, Ripp J, Trockel M. Understanding and addressing sources of anxiety among health care professionals during the COVID-19 pandemic. JAMA - J Am Med Assoc. 2020;323(21):2133-4.

18. Manzano García G, Ayala Calvo JC. The threat of COVID-19 and its influence on nursing staff burnout. J Adv Nurs. 2021:77(2):382-844. 